BONE-MARROW INFUSIONS: INTRATIBIAL AND INTRAVENOUS ROUTES COMPARED

\author{
BY
}

\author{
L. W. C. MASSEY, M.B., B.S. \\ From the Gastro-enteritis Unit, South-western Hospital
}

The bone marrow as an alternative to the venous route for injections and infusions in man was described by Henning (1940) in Germany and by Tocantins (1940) in the U.S.A. In this country the method was recommended by Barford (1943) and by Bailey (1944), and a suitable needle was devised for use in infants by Gimson (1944). Since then a large number of workers have used the method, and it was found that the intrasternal route was suitable for adults, though there was some danger of perforating the sternum, and the intratibial route for infants. Many cases of osteo-myelitis were described as following bone-marrow infusions, and in a review of the literature up to 1945 Quilligan and Turkel (1946) concluded that the bone marrow should be used only as an "emergency" route for parenteral fluids.

In this country, however, Ellison (1944) and Gunz and Dean (1945) regarded the method as a satisfactory alternative to the intravenous route, while in the U.S.A. Elston et al. (1947) came to the same conclusion, stating that the incidence of complications is "very low."

Further favourable reports have come from Higgins et al. (1947), Sutton and Kelley (1947), Williams and Lockhart (1948), and Texter and Kaump (1948) in the U.S.A., Couder (1948) in France, and from Heinild et al. (1947) in Denmark after experience with nearly 1,000 infusions.

The reported series of bone-marrow infusions in the literature together with the incidence of osteomyelitis have been compiled in Table $I$.

TABLE I.-Incidence of Osteomyelitis after Bone-marrow Infusions

\begin{tabular}{|c|c|c|c|}
\hline \multicolumn{2}{|l|}{ Author } & $\begin{array}{l}\text { Total in } \\
\text { Series }\end{array}$ & $\begin{array}{l}\text { No. of Cases of } \\
\text { Osteomyelitis }\end{array}$ \\
\hline 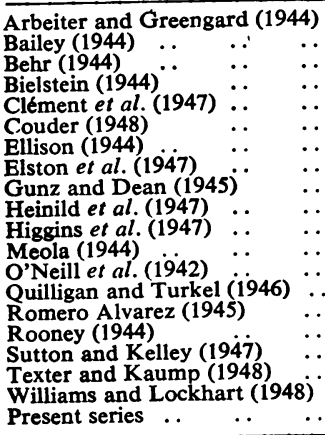 & 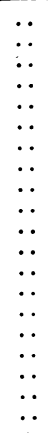 & $\begin{array}{l}35 \\
60+ \\
60+ \\
58 \\
65 \\
100+ \\
130+ \\
112 \\
35 \\
982 \\
120 \\
326 \\
116 \\
45 \\
77 \\
100 \\
200 \\
383 \\
138 \\
72\end{array}$ & $\begin{array}{l}0 \\
0 \\
0 \\
0 \\
3 \\
0 \\
5 \\
0 \\
1 * \\
5 \\
0 \\
0 \\
0 \\
1 \\
0 \\
2 \\
0 \\
2 \dagger \\
1 \\
1\end{array}$ \\
\hline & & 3,214 & 21 \\
\hline
\end{tabular}

* Gunz and Dean refer to two further cases of osteomyelitis which they do not include in their series.

Texter and Kaump gave more than one infusion through the same needle $\dagger$ Texter and Kaump gave
(325 punctures were made).

The small series have not been included-for example, 20 intrasternal blood transfusions without osteomyelitis reported by Giraud et al. (1945). A series of over 400 reported by Tocantins and O'Neill (1945), in which it is not made clear how many, if any, cases of osteomyelitis resulted, is also omitted.

\section{Comparison of the Two Methods}

Both intratibial and intravenous infusions have been used at this hospital for some years. In January, 1948, a ward for gastro-enteritis in infants was opened and both methods were used in the treatment of cases with clinical signs of dehydration. By June, 1948, 72 infusions of each kind had been successfully performed. The two series of infusions were comparable in that they were carried out by the same staff and on similar patients. Often the same patient would be treated by both methods.

The fluids used were Hartmann's solution, glucose-saline, "casydrol," diluted plasma, and blood. Our previous experience had shown that the latter two were not very satisfactory for intramedullary use, so that blood was always, and plasma usually, given intravenously. The fluids were delivered by the standard "drip" method, and in most cases the infusion was allowed to run for as long as possible.

\section{Intratibial Series}

Method.-Gimson's (1944) method was used : a local analgesic was infiltrated down to the periosteum at a point medial and below the tibial tubercle, a Gimson needle was pushed in through the cortex of the bone, a little marrow aspirated, and the needle attached to a continuous-drip apparatus. One infusion was omitted from the series because of insufficient data and 12 because there was failure to perform the bone puncture or the "drip" failed to run. These failures were in some instances due to the use of too short a needle and were unusual in the case of the more experienced operator.

Complications (Table II).-A mild periostitis was seen in all cases examined radiologically but caused no trouble. On three occasions some necrosis of the bone was seen on

TABLE II.-Complications

\begin{tabular}{|c|c|c|}
\hline & Intratibial & Intravenous \\
\hline 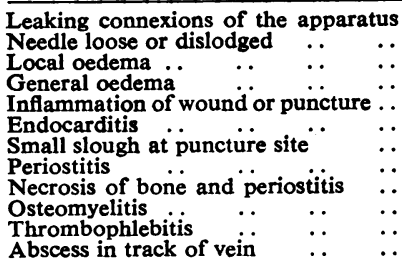 & $\begin{array}{r}3 \\
5 \\
12 \\
4 \\
7 \\
0 \\
4 \\
1 \\
3 \\
1 \\
\mathrm{Nil} \\
"\end{array}$ & $\begin{array}{r}4 \\
11 \\
28 \\
8 \\
7 \\
1 \\
\text { Nil } \\
", \\
", 6 \\
3\end{array}$ \\
\hline
\end{tabular}

the film, described by Tocantins as "pressure necrosis," but this also required no treatment. One case of osteomyelitis occurred and was transferred to surgical care. The child was not operated on, and is reported to have been discharged cured. In another case regarded as a failure the shaft of the needle broke off while being inserted and was left embedded in the bone for five months with no ill effect. For some months after the infusion most cases were left with a little nodule in the skin adherent to the bone at the site of the puncture, as noted by Elston et al. (1947). A small slough at the site of the puncture was seen four times; this was due to pressure on the skin by the needle guard where too short a needle was used. Seven other cases showed a mild infection of the puncture wound.

\section{Intravenous Series}

Method.-The saphenous vein at the ankle was usually employed ; it was exposed by a small incision under local analgesia and a double needle of the Bateman type tied in. The lumen of the vein was frequently so small that only the fine inner needle could be used.

Omitted from the series were 17 instances in which there was failure to perform the attempted infusion or in which the "drip" failed to run.

Complications (Table II).--In most of the cases some degree of phlebitis could be detected clinically in that the vein was thickened and tender on palpation. This was thought to be a physiological response. Thrombophlebitis was manifested by signs of phlebitis extending along the 
course of the vein accompanied by red, swollen, and tender areas of overlying skin. It occurred in six instances and subsided rapidly. A mild infection of the incision was found seven times.

\section{Discussion}

An examination of the records of the infusions showed that by the intratibial route an average of $40 \mathrm{oz}$. (1.14 litres) of fluid was given (Table III). The duration of the infusion

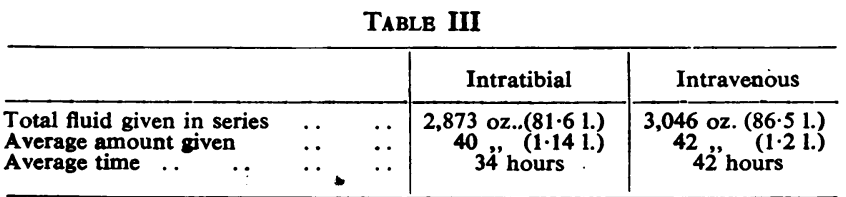

was anything from 12 hours to four or five days (average 34 hours). By the intravenous route an average of $42 \mathrm{oz}$. (1.2 litres) was given, and the duration of the infusion ranged from 12 hours to three or four days (average 42 hours). It also appeared that the maximal rate of flow of the intratibial "drip" was almost as good as that of the intravenous and quite adequate for infusions at the rate we required.

In none of the cases of intratibial or intravenous infusions were embolic or septicaemic complications noted, with the exception of one case in which the patient died after an intravenous infusion and in which "agonal endocarditis" was found at necropsy.

Local oedema occurred round the site of the intratibial needle in 12 cases and round the intravenous needle in 29 cases towards the end of the infusion. In the former the cause is probably due to fluid leaking back along the needle when it has been in the bone for some time and becomes loose, while in the latter it is probable that the needle is pushed through the vein while adjustments are being made to it or the baby is being moved for nursing purposes.

The intratibial needle is more firmly held in place than the intravenous needle and became loose in only five instances, while the latter was dislodged 11 times.

It would seem that the advantages of the intratibial method are "ease and speed in introducing the needle and its firm fixation" (Behr, 1944), while, on the other hand, the intravenous method is better for blood or plasma. It was also often found to be possible to deliver fluid at a faster rate by the intravenous route, though this was seldom required.

The disadvantage of the intratibial method is the occasional osteomyelitis, as compared with the complication of thrombophlebitis or abscesses in the track of the needle in the case of the intravenous method.

By improvements in technique and by removing the needle earlier it may be possible to reduce all these complications, and it should be noted that the reports in the literature indicate that the osteomyelitis is usually amenable to treatment, since it is provided with an artificial sinus by the needle puncture (Ellison, 1944).

However, it would be best to reserve the intramedullary infusion for those occasions when, for various reasons, the technical difficulties of the intravenous method are too great for the operator.

\section{Summary}

The literature on bone-marrow infusions is briefly mentioned and the incidence of the complication of osteomyelitis is assessed (approximately 1 in 150 cases).

Seventy-two intratibial infusions are compared with the same number of intravenous infusions.
One case of osteomyelitis is reported in the intratibial series, and the intratibial method is recommended as very satisfactory for the administration of the parenteral fluid in infants when difficulty is found with the intravenous method.

My thanks are due to Dr. J. C. Blake, physician-superintendent, for his advice and permission to use the hospital records, and to my colleagues for permitting me to include their cases in the infusion series. I wish also to thank the librarian of the Royal Society of Medicine, and Miss Helen Bayne, of the Library of the New York University, Bellevue Medical Centre, for assistance with the list of references.

\section{REFERENCES}

Arbeiter, H. I., and Greengard, J. (1944). J. Pediat., 25, 1.

Bailey, H. (1944). British Medical Journal, 1, 181.

Barford, L. J. (1943). Ibid., 1, 581.

Behr, G. (1944). Lancet, 2, 472.

Bielstein, C. M. (1944). J. Okla. med. Ass., 37, 243.

Clément, R., Gerbeaux, J., and Bouveau, G. (1947). Arch. franç. Pédiat., 4, 531.

Couder, R. (1948). Pr. méd., 56, 4.

Ellison, J. B. (1944). British Medical Journal, 1, 266.

Elston, J. T., Jaynes, R. V., Kaump, D. H., and Irwin, W. A. (1947). Amer. J. clin. Path., 17, 143.

Gimson, J. D. (1944). British Medical Journal, 1, 748.

Giraud, G., and Desmonts, T. (1944-5). Sang, 16, 437.

Gunz, F. W., and Dean, R. F. A. (1945). British Medical Journal, $1,220$.

Heinild, S., Sondergaard, T., and Tudvad, F. (1947). J. Pediat., 30, 400 .

Henning, N. (1940). Med. Klinik, 36, 724.

Higgins, J. M., Motsay, D. S., and Bailey, J. F. (1947). Guthrie clin. Bull., 17, 15 .

Meola, F. (1944). J. Pediat., 25, 13

O'Neill, J. F., Tocantins, L. M., and Price, A. H. (1942). N.C. med. J., 3,495 .

Quilligan, J. J., and Turkel, H. (1946). Amer. J. Dis. Child., 71, 457.

Romero Alverez, A. M. (1945). Sem. méd., B. Aires, 2, 609.

Rooney, E. F. (1944). Arch. Pediat., 61, 611 .

Sutton, M., and Kelley, G. P. (1947). N. Orleans med. surg. J., 100. 266

Texter, E. C., and Kaump, D. H. (1948). J. Mich. med. Soc., 47, 1002.

Tocantins, L. M. (1940). Proc. Soc. exp. Biol., N.Y., 45, 292.

Wi1 and O'Neill, J. F. (1945). Ann. Surg., 122, 266.

Williams, J. C., and Lockhart, J. (1948). Penn. med. J., 51, 767.

\section{Medical Memoranda}

\section{Transfixion by a Muck Fork}

Accidental transfixion by a muck fork or similar tined implement is not uncommon in country districts. The following case is reported in order to stress the importance of leaving the implement in situ until the patient reaches hospital.

\section{CASE Report}

The patient, a lad of 16 , was admitted to the County Infirmary, Louth, at 6 p.m. on September 19, 1949. At 5 p.m. he had fallen off a lorry load of straw on to the

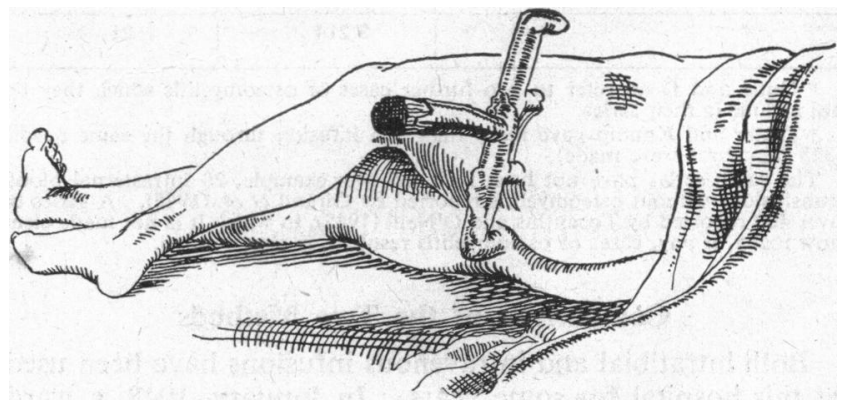

points of a muck fork. When seen just after admission he was lying on his right side with the business end of the fork transfixing him from behind forwards as in the accompanying drawing. The fork was thickly coated with manure. At the 